\title{
Application of amphoteric polymers in the process of leather post-tanning
}

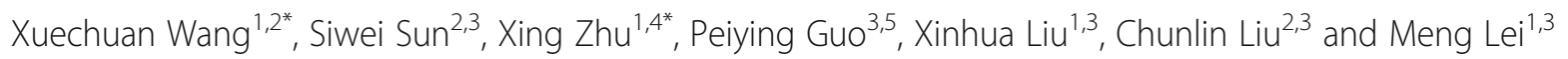

\begin{abstract}
With the characteristics of controllable charge and environmental friendliness, amphoteric polymers can be used in post-tanning process to solve the problems that arise during leather making and are caused by the low absorption rate of single-charge chemicals, incompatibility with new tanning methods, and complex operation process. In this review, the structure, performance, and preparation of amphoteric polymers are reported. Then, the charge change of collagen during different tanning and pH treatments is introduced. Finally, the application and development of amphoteric polymers during the post-tanning process of leather making are discussed. This review has certain guiding significance to the preparation and application of amphoteric polymers for tanning system.
\end{abstract}

Keywords: Amphoteric polymer, Leather making, Post-tanning, Research and application, Progress

\section{Introduction}

Tanning is one of the oldest industries in human history. During the tanning process, raw hides are transformed into leather that can be directly used through complex treatment and cross-linking modification [1]. The post-tanning section of leather making directly determines the wearability and color style of finished products, which is a key step after tanning. The main component of raw skin is collagen, which has amphoteric properties and controllable charge because it contains both acidic and basic groups [2-4]. During leather making, both chemicals and $\mathrm{pH}$ affect the charge of collagen. Chemicals consume acidic and basic groups of collagen, and the added chemicals carry a certain amount of charge. At the same time, the changed $\mathrm{pH}$ of the bath can make collagen deviate from its isoelectric point (pI) region $[5,6]$. Different substances diversely affect collagen. The use of a single charged material to interact with collagen may cause many problems such as excessive surface binding, poor

\footnotetext{
*Correspondence: wxc-mail@163.com; zhuxing@sust.edu.cn

'College of Bioresources Chemical and Materials Engineering, Shaanxi University of Science and Technology, Xi'an, Shaanxi 710021, People's Republic of China

Full list of author information is available at the end of the article
}

permeability, low absorption of the subsequent same-charge substance, poor compatibility, and complex process [7-10]. In comparison, apart from having the functional properties of single-charge material, amphoteric polymer can also adjust its charge with a change in the structure and $\mathrm{pH}$ to meet the requirements of collagen. Its main characteristics are as follows: (1) regulation of collagen charge; (2) provision of synergistic effect for the absorption of matching chemicals; (3) process simplicity; and (4) possession of good environmental compatibility and low irritation [11-13]. Therefore, the development of amphoteric polymers for leather making is essential for the research on leather making chemicals. Our group has successfully developed several excellent amphoteric chemicals for leather making, such as an amphoteric polyurethane retanning agent with an aldehyde removal function, an amphoteric collagen-based retanning agent with a filling function, and an amphoteric polymer fatliquoring agent that is based on ionic liquid. On the basis of our previous studies, this paper reviews the structure and properties of amphoteric polymers, amphoteric properties of collagen fibers, and the research status of amphoteric polymers during posttanning. 


\section{Structure, properties, and synthesis methods of amphoteric polymers}

\subsection{Structure and properties of amphoteric polymers}

Amphoteric polymers contain both anionic and cationic groups in the same molecular structure [14]. Therefore, it has the characteristics of pI, good compatibility, adjustable molecular charge, and low toxicity [15-18]. Amphoteric polymers can be classified in different ways. One of the classifications is based on the structural characteristics of polymers, the skeleton structure, and the types of anionic and cationic groups [19].

According to the structure of main skeleton, amphoteric polymers can be divided into carbon skeleton, hetero skeleton, and elemental organic skeleton. The skeleton structures of carbon chain amphoteric polymers are composed of carbon atoms. The skeletons of polyolefin are more common such as a polymethacrylamide framework [20], polymethacrylate skeleton [21], polyethylene pyridine skeleton, and acrylamide and maleic anhydride copolymer skeleton [22]. In addition to carbon atoms, there are oxygen, nitrogen, phosphorus, sulfur, and other heteroatoms in the main skeleton structure of heterochain amphoteric polymers, including polyurethane and polyester amphoteric polymers. Some of the natural polymers also belong to this type including polypeptide skeletons $[23,24]$ and phosphatidyl choline $[25,26]$. Elemental organic amphoteric polymers are semi-organic polymers. The main molecular skeleton is mainly composed of inorganic elements or metal atoms; however, the side groups are mostly organic groups such as amphoteric hydrotalcite organic polymers. The introduction of polymer frameworks with different structural types and properties greatly enriched the properties of amphoteric polymers.

The positive charge centers of amphoteric polymers are mainly nitrogen, phosphorus, and sulfur atoms, which can form cations of quaternary ammonium, quaternary phosphonium, and sulfonium salts. Among them, the most common one is nitrogen atom, which can be divided into $\mathrm{pH}$-insensitive and $\mathrm{pH}$-sensitive types according to the functional groups formed by nitrogen atom. The charge amount of $\mathrm{pH}$-insensitive nitrogen atoms does not change in a wide range of $\mathrm{pH}$ such as the quaternary amino group in betaine amphoteric polymers. Because in the outermost layer of nitrogen atom four electrons form covalent bond with outer electron of carbon atom respectively and one electron is lost, the quaternary amino group always has a stable positive ion, in which nitrogen atom transfer electrons difficultly with the change of $\mathrm{pH}$. The charge amount of $\mathrm{pH}$-sensitive nitrogen atom changes with the $\mathrm{pH}$ environment, such as primary amino group, secondary amino group and tertiary amino group in polypeptide molecules, in which the nitrogen atoms can get or lose electrons. Negative charge centers are loaded on negatively charged acidic groups such as carboxylic acid, sulfonic acid, sulfuric acid, sulfite, and phosphate groups [14]. Different amphoteric polymers can be constructed by pairwise combination of different positive and negative charge centers [27].

\subsection{Synthetic methods of amphoteric polymers}

Amphoteric polymers can be synthesized by monomer polymerization or polymer molecular modification. The approaches can be divided into direct and indirect synthesis. The former refers to the preparation of amphoteric polymers by the polymerization of amphoteric small molecule monomers or the copolymerization of anionic monomers and cationic monomers. The common amphoteric monomers are acrylamide betaine, methacrylate betaine, and vinylpyridine betaine [22]. The main polymerization method is radical polymerization. In recent years, reactive controlled radical polymerization has been widely used in the synthesis of amphoteric polymers such as atom transfer radical polymerization (ATRP) and reversible addition fragmentation chain transfer (RAFT) radical polymerization. Such as, Skinner et al. [28] prepared amphoteric block copolymers via ATRP method, in which phosphorylcholine and choline phosphate methacrylate were used as monomers and a difunctional poly (propylene oxide) was used as macroinitiator. Ohno et al. [29] successfully grafted amphoteric polymer brushes onto a glass substrate via RAFT. In this surface grafting polymerization, methacrylic acid and 2-(dimethylamino) ethyl methacrylate were used as monomers, (n-butylsulfanylthiocarbonylsulfanyl-2-methyl propionic acid) was used as free chain transfer agent and (4,4'-azobis (4-cyanopentanoic acid)) was used as initiator. The latter refers to the method of modifying the main chain or side chain of polymer molecules by introducing anion and cation groups. In some studies, chloroacetic acid has been used to quaternary ammoniate the tertiary amine group of the polymer to obtain amphoteric polymer with a carboxyl betaine structure. Amphoteric polymers can also be obtained by click chemistry reactions [30] between the sulfhydryl groups of zwitterion and alkene or alkyne functional groups of polymers. In addition, polymer precursors with protective groups can be prepared to obtain amphoteric polymers by deprotection (Fig. 1).

\section{Amphoteric properties of collagen after tanning}

The pI of crust leather is an important index of its amphoteric properties, at which the total number of positive and negative charges in leather are equal. It directly affected the charge of leather in different $\mathrm{pH}$ and the choice of chemical and technology during leather making. Leather is a polymer matrix with a three- 


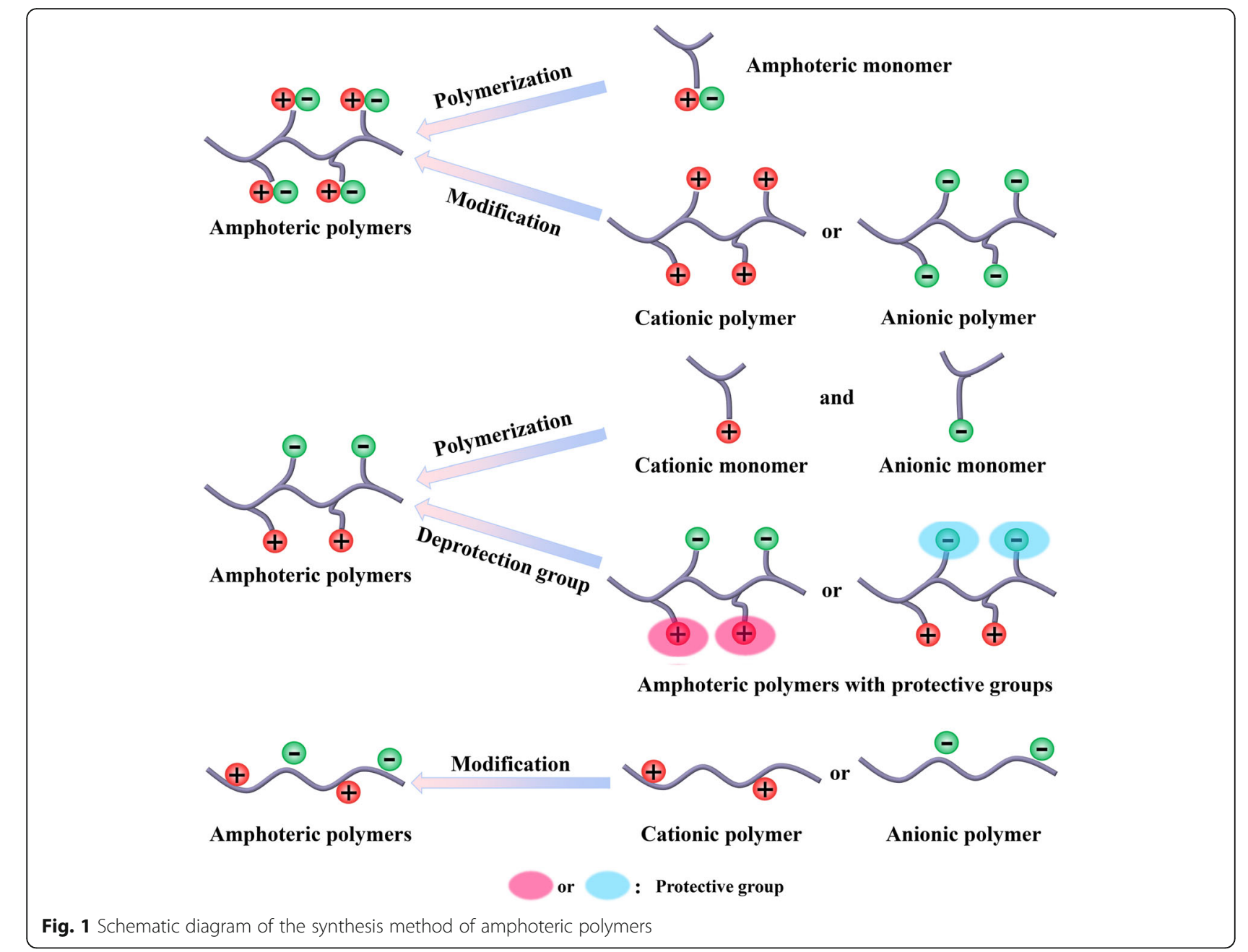

Amphoteric polymers with protective groups

Amphoteric polymers
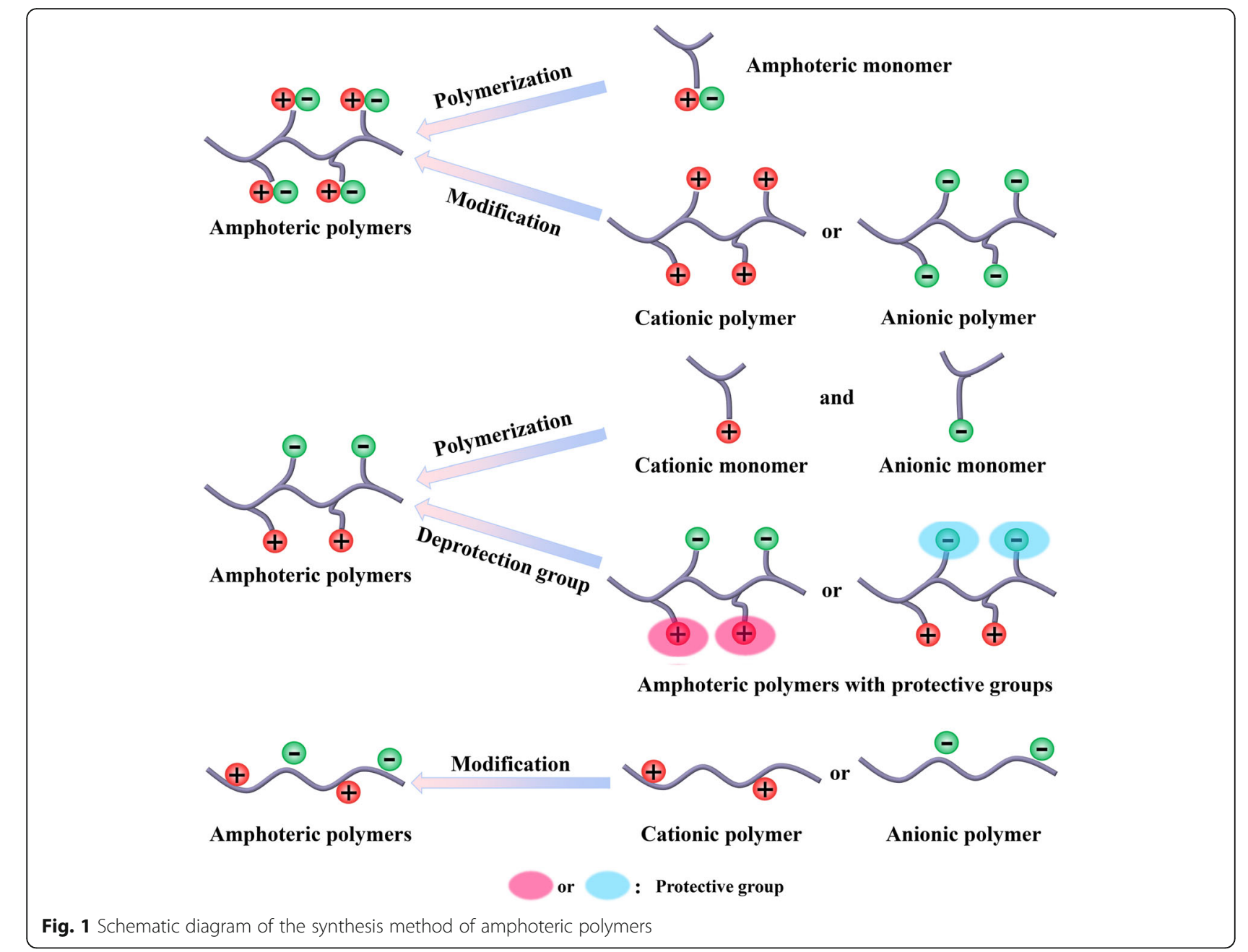

dimensional network structure woven by collagen fibers. Collagen fiber is not only the main component of leather but also a typical amphoteric polymer. The amino group on the side chain of basic amino acid residue and the carboxyl group on the side chain of acid amino acid residue in collagen can bind or release hydrogen ions $\left(\mathrm{H}^{+}\right)$ and even ionize in aqueous solutions, which results in the collagen fiber with positive or negative charges [31, 32]. During the process of leather making, chemicals can interact with collagen matrix. Chemicals can consume the acidic and/or basic groups of collagen. Furthermore, the added materials have a certain amount of charge, which will also affect the pI of leather. Figure 2a shows the mechanism of action between several tanning agents and polar groups in collagen fibers and the $\mathrm{pI}$ of leather after tanning [33, 34].

The $\mathrm{pI}$ of pickled skin is 5.4, which is attributed to the hydrolysis of the peptide bond of collagen and deamidation of asparagine and glutamine residues. The chrome tanning agent is mainly coordinated with the carboxyl group in skin collagen, and the metal chromium complex is cationic. Therefore, the pI (7.2) of chrometanned leather was increased. The pI of vegetabletanned leather is 4.6. This occurs because the vegetable tanning agent is the polyphenol polymer; thus, the hydroxyl group in the molecule can combine with the amino group of collagens by hydrogen bond. The pI of syntan-tanned leather is 4.2 . In the preparation of syntan, sulfonation is often used to modify polyphenols to improve its combinability and water solubility. Sulfonic acid group of syntan can combine with the collagen amino group by an ionic bond, which increases the negative charge in the skin. Aldehyde tanning agent covalently combines with amino groups in collagen, which makes the pI of the tanned skin 4.8. In the newly developed white wet leather without chrome, the pI of F-90tanned white wet leather is 4.5 . F-90 is a modified product of cyanuric chloride and contains chlorine atom, which can be covalently bonded with amino groups in collagen. The amphoteric tanning agent TWT can consume amino groups in collagen fibers through aldehyde groups, but its amino groups can increase the number of 


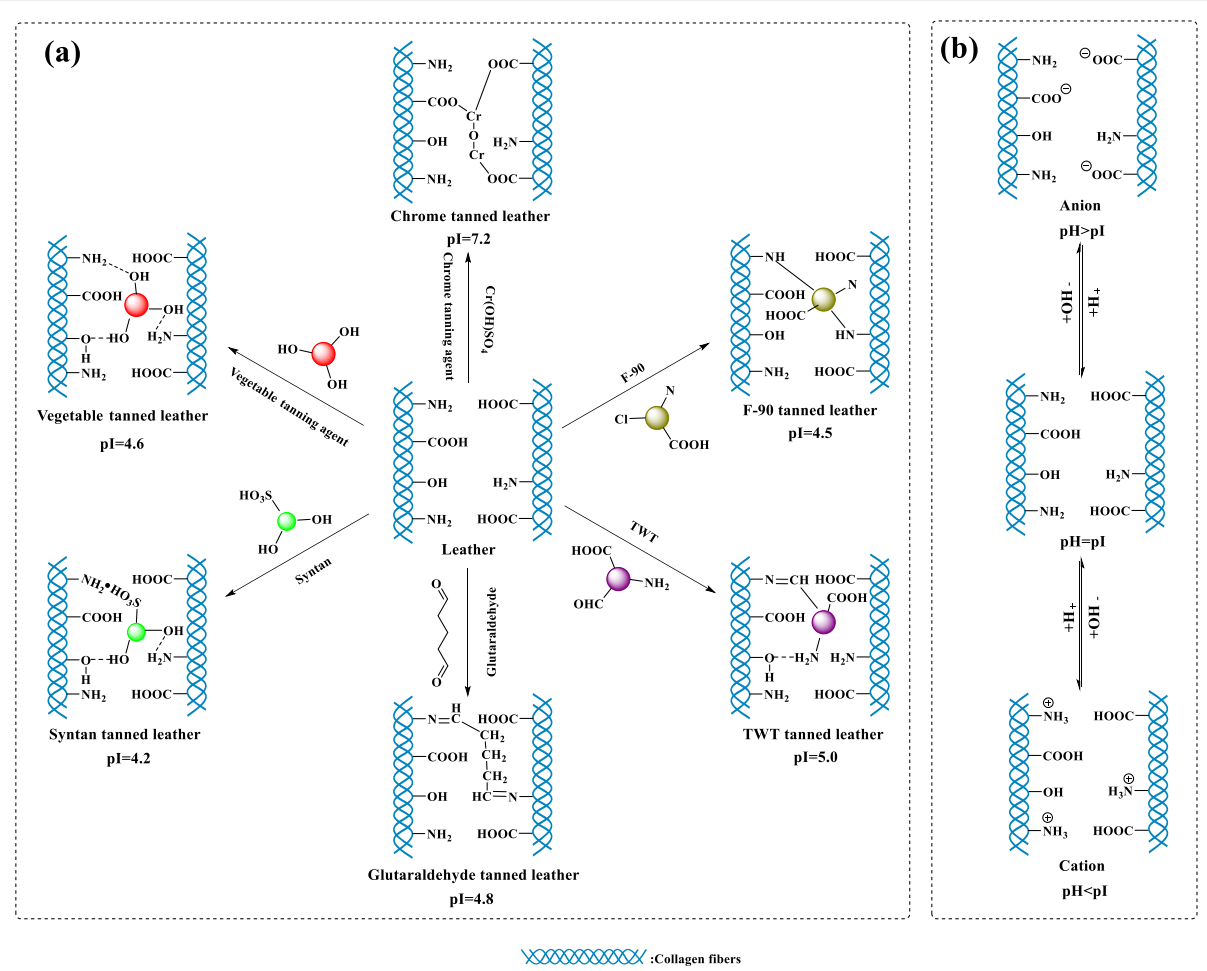

Fig. 2 a Mechanism of action between several tanning agents and polar groups in collagen fibers and the isoelectric points of leather after tanning [33-35]; and $\mathbf{b}$ electric charge of leather under different $\mathrm{pH}$ conditions

cations in collagen, which leads to higher pI (5) than that of other tanning agents [34, 35].

At the same time, during the process of leather making, the penetration and combination of chemicals in the leather are often controlled by adjusting the $\mathrm{pH}$ of bath solution. When $\mathrm{pH}$ is equal to $\mathrm{pI}$, the collagen shows neutrality, which improves the penetration of chemicals. When $\mathrm{pH}$ is greater than $\mathrm{pI}$, the charge of collagen is anionic. When $\mathrm{pH}$ is less than $\mathrm{pI}$, the charge of collagen is cationic. When $\mathrm{pH}$ deviates further from $\mathrm{pI}$, the amount of charge on leather increases, which is conducive to the combination of chemicals with different charges (Fig. 2b) [36, 37]. Therefore, the charge change of the collagen amphoteric polymers substrate during leather making is extremely complicated.

\section{Research progress of amphoteric polymer during post-tanning}

The charges of amphoteric polymers can be regulated in a wide $\mathrm{pH}$ range, which results in good compatibility. In addition, the introduction of amphoteric polymers into leather can further improve the charge characteristics of skin collagen to increase the absorption of subsequent dyeing and finishing chemicals and adapt the complex changes in the charge of collagen during leather making. The process of leather making after tanning in an aqueous environment is called post-tanning stage, which mainly includes retanning, fatliquoring, and dyeing. The application of amphoteric polymers in different stages of post-tanning is as follows.

\subsection{Retanning agent}

An increasing demand for consumption and environmental protection result in the development of multifunctional, high-performance, and environmentally friendly tanning agents. Retanning is an essential tanning technique. The use of amphoteric polymers in retanning can change the charge of leather and also provide leather more functional properties. The vinyl skeleton polymer is the main structure of the amphoteric retanning agent. Jin et al. [38, 39] have prepared an amphoteric acrylic acid retanning agent with acrylic acid and methacryloyl ethyl trimethyl ammonium chloride. Li et al. [40] have used methacrylic acid, maleic anhydride monopolyethylene glycol ester, and dimethyldiallylammonium chloride to synthesize an amphoteric retanning agent. Ma's group [41-46] has even designed and synthesized a series of amphoteric vinyl polymers with diallyl dimethyl ammonium chloride as a cationic monomer (Fig. 3a-d). First, a binary copolymer was synthesized by the copolymerization of diallyl dimethyl ammonium chloride and acrylic acid, which successfully improved the color fading phenomenon of traditional acrylic retanning agent. However, the excessive cationic monomer in the 
(a)

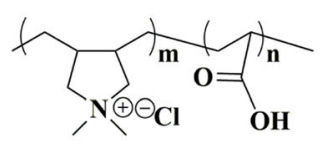

(c)

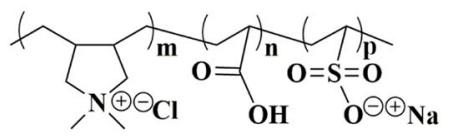

(b)

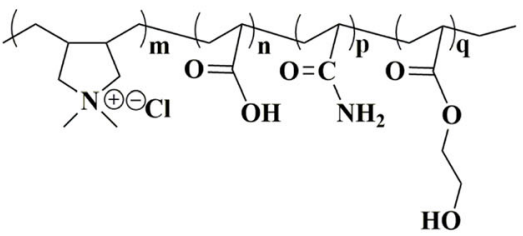

(d)

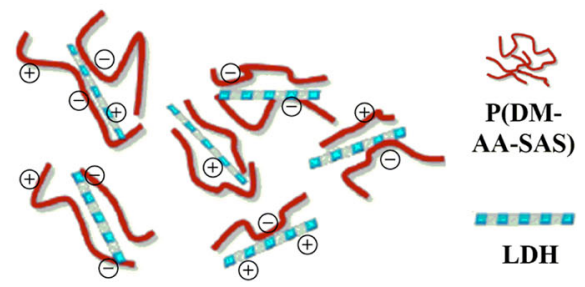

Fig. 3 a Poly (diallyl dimethyl ammonium chloride-acrylic acid); b poly (diallyl dimethyl ammonium chloride-acrylic acid-acrylamidehydroxyethyl acrylate); c poly (diallyl dimethyl ammonium chloride-acrylic acid-sodium allyl sulfonate); and $\mathbf{d}$ poly (diallyl dimethyl ammonium chloride-acrylic acid-sodium allyl sulfonate)/layered double hydroxide nanocomposite (P (DM-AA-SAS)/LDH) [41-46]

molecule was weak in combination with chrome-tanned leather. To further improve the tanning effect of the polymer, a polyampholytic polymer retanning agent was prepared by introducing acrylamide and hydroxyethyl acrylate. After being applied to chromed leather, the dyeing depth (K/S value) of dyed leather sample is increased by $50.8 \%$. Then amphoteric polymers with sulfonic groups were synthesized, which could inhibit the expansion of naked leather. The amphoteric polymer/hydrotalcite nanocomposites with an organic-inorganic framework structure were prepared by introducing layered double hydroxides (LDH), which could further improve the absorption of anionic materials during the post-tanning process of leather to obtain leather with substantial darkening, different color, and softness. The introduction of zwitterions increased the positive charge of leather and the application of the amphoteric retanning agent improved the dyeing performance of chromed leather. These characteristics are obtained because of the electrovalence and hydrogen bonding interactions between carboxyl and sulfonic anions and quaternary amino cations in amphoteric polymers with collagen. Moreover, the selection of biomass materials provides a method for the sustainable development of leather [47]. Lv et al. [48] have synthesized an amphoteric retanning agent via the copolymerization of biomass material chitosan with methacrylic acid and acrylamide and applied it to the leather retanning process. In addition to good dyeing properties, zwitterions and chitosan have excellent antibacterial properties.

The manufacturing technology of organic chrome-free ecological leather is an important direction for the sustainable development of the leather industry. However, the positive charge of tanned white wet leather is weakened, and the absorption rate of traditional anionic dyeing and finishing materials is reduced, which affects the quality of finished leather. The amphoteric structure has both positive and negative charges, which provide a feasible solution for solving the aforementioned problems. Our group [49-51] uses polyurethane as the skeleton structure to synthesize functional retanning agents. One is the combined amphoteric retanning agent containing an aldehyde group, which is produced by introducing 2 , 4-dihydroxybenzaldehyde. The other is an amphoteric retanning agent with an aldehyde removal function, which is produced by introducing chromotropic acid and collagen. Then, they were applied to vegetable, F-90, and aldehyde tanned leather. It was observed that the K/ $\mathrm{S}$ of leather surface after retanning and dyeing was higher than that of leather with an acrylic resin retanning agent. The dye absorption rate of vegetable leather reached $90.00 \%$, and the free formaldehyde removal rate of formaldehyde reached $80.95 \%$. To leather retanned by acrylic resin, the dye absorption rate of vegetable leather was only reached $85.00 \%$, and the free formaldehyde removal rate of formaldehyde reached $1.40 \%$. The properties of chrome-free tanned leather were improved, and the types of matching chemicals were enriched. To further promote the green development of leather chemicals, a new type of biomass amphoteric leather retanning agent with the function of reducing free formaldehyde was prepared by hydrolyzed collagen and oxidized tannin extract as raw materials [52]. It can improve the absorption of cationic and anionic dyes in vegetabletanned leather (Fig. 4a). At the same time, the amphoteric amino group in collagen can capture formaldehyde via the Schiff base reaction; carboxyl group can also bind a certain amount of formaldehyde through van der Waals force and hydrogen bonding, and the pore structure of collagen can also physically adsorb formaldehyde (Fig. 4b). This information provides guidance for the research on chrome-free tanning matching chemicals. 

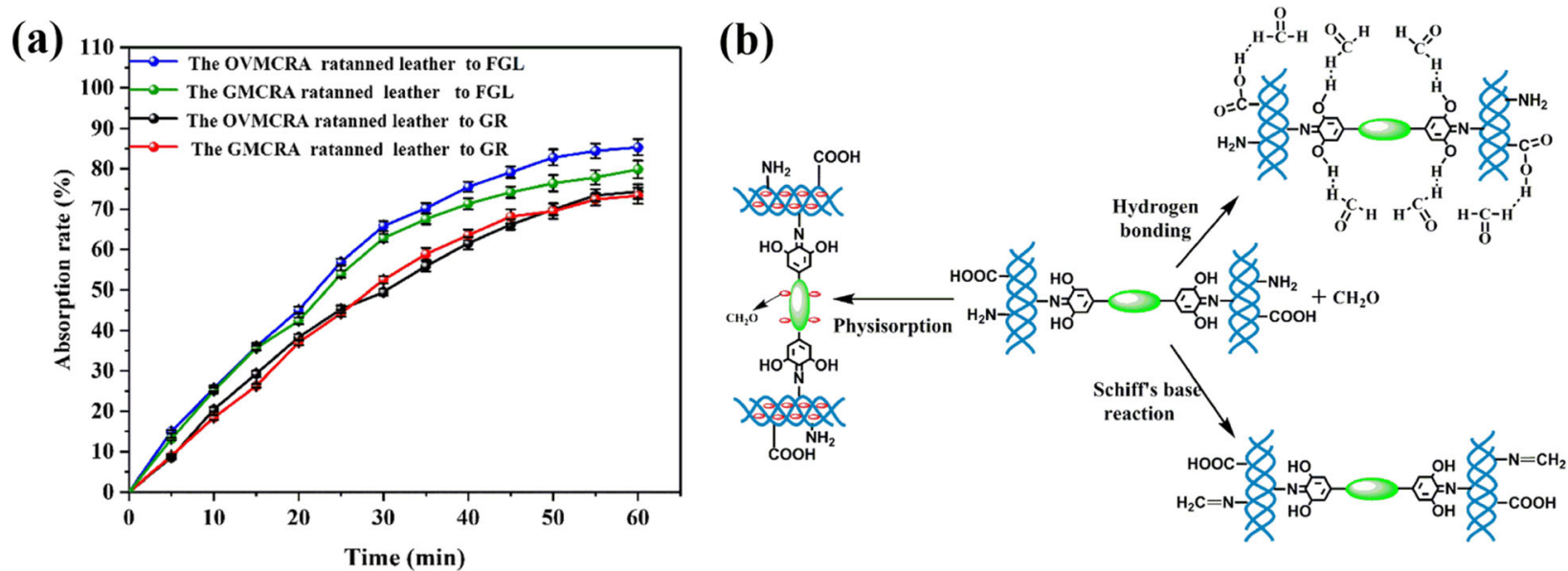

Fig. 4 a Absorption rate of the retanned leather to dyes. FGL: blue cationic dye-FGL, GR: deep blue acid dye-GR, OVMCRA: oxidized valonia extract-modified collagen retanning agent, GMCRA: commercial modified protein retanning agent; and $\mathbf{b}$ Reaction mechanism of free formaldehyde removal [49]. Copyright @ 2020, Elsevier

\subsection{Fatliquoring agent}

Fatliquor is one of the key chemicals to determine the quality of resulted leather. Most amphoteric fatliquors have amphiphilic structures with hydrophilic ionic groups and hydrophobic alkyl long chains. Their surfactants and emulsifying power can wrap oil into the leather interior. At the same time, amphoteric properties can promote the combination of amphoteric fatliquor and collagen fiber. Lv et al. [53] prepared amphoteric fatliquor used the cheap rapeseed oil as raw material, which was partially amidated with ethylenediamine to introduce the amino group and polymerized with acrylic acid to introduce carboxyl group. The results showed that the flexibility of fatliquored leather samples and the absorption rate of fatliquor were higher than those of commercial products. Zheng et al. [54] have obtained a new amphoteric fatliquoring agent in three steps. The first step is to esterify fatty acids with diethanolamine. Diethanolamine can provide cation and combined with anion to form amphoteric polymer. Then, the resulting product is reacted with maleic anhydride and finally sulfonated. Janardhanan et al. [55] prepared a novel amphoteric surfactant diethylamino lauryl itaconic acid ester by mixing diethylamine and dodecyl itaconate anionic polymerizable surfactant. It was determined that they had deeper penetration and better fatliquoring performance when it was applied to leather. To further adapt to the development of the tanning system, our group [11] used free radical polymerization to synthesize the amphoteric polymer surfactant that was based on ionic liquid. The fatliquoring agent which named as $\mathrm{p}$ (DM-co-[DDVIM]Br) PS was synthesized from 1dodecyl-3-vinylimidazole bromide [DDVIM] $\mathrm{Br}$, dimethylaminoethyl methacrylate (DM) and 1,3-propanesultone as monomers. Using zwitterions and good solvent properties of ionic liquids, the fatliquoring agent prepared by mixing the amphoteric polymer surfactant with oil had an absorption rate of $99.26 \%$, loose leather fibers, and high softness. The obtained results showed that the binding affinity between collagen and dyes was improved during the fatliquoring process. The dye absorption rate was $99.01 \%$. The fatliquoring and dye solutions were clear and considerably better than those of an anionic fatliquor on the market (Fig. 5). Therefore, our study helps to improve the absorption rate of anionic post-tanning materials, reduce the pollution caused by the use of chrome tanning agent, and provide a new way for clean production of leather industry. Except carboxyl group, the phosphate group is also the conventional anionic group in the amphoteric polymer, which has a better binding force with leather and makes the resulted leather have an excellent mercerizing and oil moistening feeling [56]. Our group [57] has further synthesized amphoteric phosphate surfactants using polyphosphoric acid as a phosphorylating agent. The surface tension of phosphate ester surfactant is better than that of dodecyl trimethyl ammonium bromide and sodium lauryl sulfate owing to the mutual attraction between zwitterions. It can be used during leather fatliquoring. Amphoteric fatliquor can improve the binding force with collagen fiber through its zwitterionic properties and promote the absorption of fatliquor to make softer leather.

\subsection{Other materials}

In addition, amphoteric polymers are essential during the dyeing process. Ballús et al. [58] have added amphoteric dyeing auxiliaries in leather dyeing and determined that these amphoteric dyeing auxiliaries can considerably improve the dye uptake. Luo et al. [59] have synthesized amphoteric polymer additives by the radical 
(a)

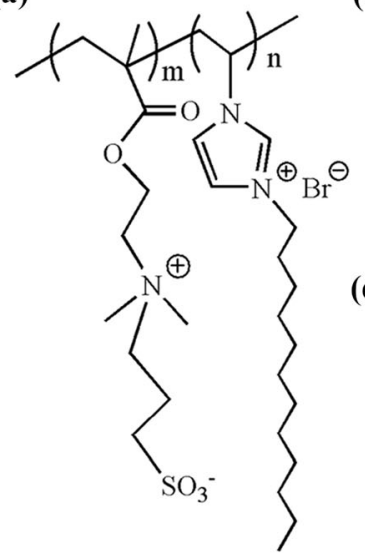

(b)

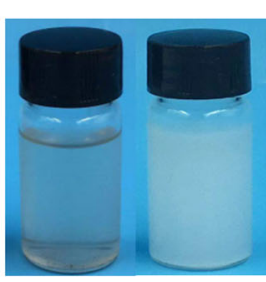

(d)

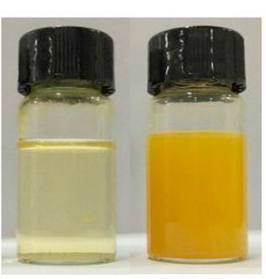

(c)

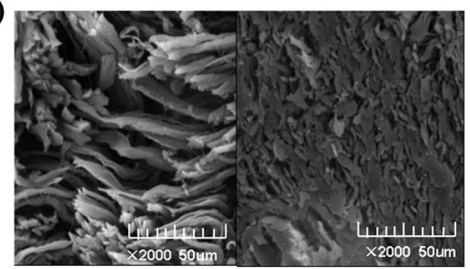

(e)

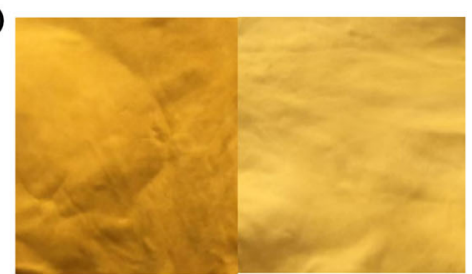

Fig. 5 a The structure of liquid-based fatliquor, p (DM-Co-[DDVIM]Br)PS; b absorption of the fatliquoring agent, left: $p$ (DM-co-[DDVIM]Br) PS, right: commercial fatliquor; c looseness of fatliquored leather, left: with p (DM-co-[DDVIM]Br)-PS, right: without any fatliquor; $\mathbf{d}$ absorption of dyeing; and e color of dyed leather, left: with p (DM-co-[DDVIM]Br) PS, right: with commercial fatliquor [11]. Copyright @ 2020, Elsevier

copolymerization of methacrylic acid, sodium methallylsulfonate, and diallyl dimethyl ammonium chloride using ammonium persulfate. The application of amphoteric polymer additives during the absorption of dyes and fatliquors in chrome-free leather shows that they have a strong auxiliary absorption capacity. The absorption rate of dyes and fatliquors is $>96 \%$.

\section{Conclusions and prospects}

During the post-tanning process of leather making, the selection of suitable amphoteric polymer materials based on the structural characteristics of collagen fibers in different tanning processes can meet the processing requirements of different leather samples and also give the resulted leather excellent properties. In addition, it is an important way for the clean production of leather. The research directions of amphoteric polymers for posttanning of leather can be performed on the basis of the following aspects.

\subsection{Development of amphoteric polymers with different structures for leather making}

The current structure of amphoteric polymers used in leather making is mainly the polyethylene skeleton structure with low variety and single performance. Thus, there is a need to develop more amphoteric polymers with different skeleton structures and anions and cations. For example, leather waste collagen, which is an amphoteric polymer, can be applied in leather processing through modification. However, the previous modification method was mainly through the SchottenBauman reaction, which used irritant raw materials and produced salts and volatile organic compounds. Therefore, the green method can be used to endow the collagen more functional characteristics, which allows the recycling of waste leather and increasing the variety of amphoteric polymers to be applied in leather posttanning materials. What's more, Phosphate ester group, which is one of the functional amphoteric leather chemicals, can increase the absorption rate of chemical used in leather making and improve the fullness and handle of leather.

\subsection{Study on the interaction mechanism between amphoteric polymers and leather}

Although the effect of amphoteric substances on leather properties has been reported, there are few systematic studies on the interaction mechanism and structure-activity relationship between amphoteric polymers and leather. Therefore, it is suggested that the influence of amphoteric polymers with different pI, skeleton structure, and anionic ions on leather structure and properties should be systematically studied to explore the structure-activity relationship between amphoteric polymers and leather properties. In addition, the influence of amphoteric polymer on the charge of leather with different $\mathrm{pI}$ can be explored under different $\mathrm{pH}$ conditions. By conducting the aforementioned studies, the mechanism of the interaction between amphoteric polymers and leather can be revealed to guide the development and application of amphoteric polymers.

\subsection{Exploration of characterization methods}

The current detection methods of amphoteric polymers and their application performance in leather mostly refer to the detection methods in other fields, which have the following drawbacks: i.e., poor applicability of detection instruments, complexity of sample preparation and detection methods, and high detection result errors. It is necessary to explore the detection method with higher 
matching and simpler process such as the charge of amphoteric polymer changes with $\mathrm{pH}$, distribution of amphoteric polymer in leather without special elements, and detection of $\mathrm{pI}$ of solid materials.

\subsection{Clean application process of amphoteric materials in post-tanning}

Ionic properties enable amphoteric post-tanning materials to be applied in the processing of crust with different $\mathrm{pI}$ in a wider $\mathrm{pH}$ range. For example, the amphoteric fatliquor with a higher $\mathrm{pI}$ can achieve higher absorption rate without the acid-adding process after fatliquoring. Therefore, it is worthy to optimize the tanning process of amphoteric materials to simplify the traditional posttanning process, reduce the use of chemicals, and promote clean leather production.

\section{Acknowledgments}

We are grateful the National Key Research and Development Program of China (2017YFB0308500) and National Natural Science Foundation of China (22078183) for financial supports of our research.

\section{Authors' contributions}

XW contributed to the investigation, funding acquisition and conceptualization. SS designed the frame, collected the data and wrote the original draft. $X Z$ added a corrective to the manuscripts. PG corrected the grammar. $\mathrm{XL}$ contributed to the investigation and the guidance of professional knowledge. CL typeset picture. ML collated references. All authors read and approved the final manuscript.

\section{Authors' information}

Not applicable.

\section{Funding}

National Key Research and Development Program of China

(2017YFB0308500) and National Natural Science Foundation of China (22078183).

\section{Availability of data and materials \\ Not applicable.}

\section{Competing interests}

The authors declare that they have no competing interests.

\section{Author details}

${ }^{1}$ College of Bioresources Chemical and Materials Engineering, Shaanxi University of Science and Technology, Xi'an, Shaanxi 710021, People's Republic of China. ${ }^{2}$ College of Chemistry and Chemical Engineering, Shaanxi University of Science and Technology, Xi'an, Shaanxi 710021, People's Republic of China. ${ }^{3}$ Institute of Biomass and Functional Materials, Xi'an, Shaanxi 710021, People's Republic of China. ${ }^{4}$ National Demonstration Center for Experimental Light Chemistry Engineering Education, Shaanxi University of Science and Technology, Xi'an, Shaanxi 710021, People's Republic of China. ${ }^{5}$ College of Arts and Science, Shaanxi University of Science and Technology, Xi'an, Shaanxi 710021, People's Republic of China.

Received: 6 August 2020 Accepted: 20 January 2021

Published online: 20 February 2021

\section{References}

1. Li YC, Guo RJ, Lu WH, Zhu DY. Research progress on resource utilization of leather solid waste. J Leath Sci Eng. 2019;1(3):1-17.

2. Whelan A, Duffy J, Gaul RT, Reilly DO, Nolan DR, Gunning P, Lally C, Murphy BP. Collagen fibre orientation and dispersion govern ultimate tensile strength, stiffness and the fatigue performance of bovine pericardium. J Mech Behav Biomed. 2019;90:54-60.
3. Liu SS, Li Q, Li GY. Investigation of the solubility and dispersion degree of calf skin collagen in ionic liquids. J Leath Sci Eng. 2019;1(3):18-29.

4. Shen LR, Bu HH, Yang H, Xu SC, Li GY. pH-responsive variation of biomineralization via collagen self-assembly and the simultaneous formation of apatite minerals. J Appl Polym Sci. 2020;137(29):48876.

5. Zakharkina OL, Sergeeva EA, Kirillin MY, Ignatieva NY. Analysis of laserinduced modification of collagen structure using nonlinear optical microscopy. Quantum Electron. 2020;50(1):76-80.

6. Li Q, Wang YP, Xiao X, Zhong R, Liao JL, Guo JL, Liao XP, Shi B. Research on $\mathrm{X}$-ray shielding performance of wearable $\mathrm{Bi} / \mathrm{Ce}$-natural leather composite materials. J Hazard Mater. 2020:398:122943.

7. Huang $W L$, Song $Y, Y u$ Y, Wang $Y N$, Bi S. Interaction between retanning agents and wet white tanned by a novel bimetal complex tanning agent. J Leath Sci Eng. 2020;2(8):1-9.

8. Franco GT, Otoni CG, Lodi BD, Lorevice MV, Moura MRD, Mattoso LHC. Escalating the technical bounds for the production of cellulose-aided peach leathers: from the benchtop to the pilot plant. Carbohydr Polym. 2020;245:116437.

9. Ma YJ, Gao F, Yang WH, Shan ZH. Analysis of free aniline in chrome-free leather accelerated aging. Spectrochim Acta A: Mol Biomol Spectros. 2020; 238:118402.

10. Basumatary B, Bhattacharya S, Das AB. Olive (Elaeagnus latifolia) pulp and leather: characterization after thermal treatment and interrelations among quality attributes. J Food Eng. 2020;278:109948.

11. Hao DY, Wang XC, Liu XH, Zhu X, Sun SW, Li J, Yue OY. A novel eco-friendly imidazole ionic liquids based amphoteric polymers for high performance fatliquoring in chromium-free tanned leather production. J Hazard Mater. 2020:399:123048.

12. Dwivedi SP, Saxena A. Extraction of collagen powder from chrome containing leather waste and its composites with alumina employing different casting techniques. Mater Chem Phys. 2020;253:123274.

13. Jiang GC, Wang K, He YB, Yang LL, Li XL, Deng Y. Synthesis of an amphoteric polymer as a high-temperature-resistant shale stabilizer in water-based drilling fluids. J Appl Polym Sci. 2020;137(35):1-13.

14. Lamch L, Witek K, Jarek E, Oblqk E, Warszynski P, Wilk KA. New mild amphoteric sulfohydroxybetaine-type surfactants containing different labile spacers: synthesis, surface properties and performance [J]. J Colloid Interface Sci. 2020;558:220-9.

15. Wang F, Yang HB, Li ML, Kang X, Zhang XF, Zhang HW, Zhao H, Kang WL, Sarsenbekuly B, Aidarova S, Gabdullin M. Study on stabilization of emulsion formed by the supramolecular system of amphiphilic polymer and sodium polyacrylic acid. J Mol Liq. 2020;314:113644.

16. Fang CJ, Zhang XY, Gong XN, Feng WL, Zhu LP, Matsuyama H. Enhancing membrane surface antifouling by implanting amphiphilic polymer brushes using a swelling induced entrapment technique. Colloids Surf B Biointerfaces. 2020;195:111212.

17. Huang CS, Jakubowski K, Ulrich S, Yakunin S, Clerc M, Toncelli C, Rossi RM, Kovalenko MV, Boesel LF. Nano-domains assisted energy transfer in amphiphilic polymer conetworks for wearable luminescent solar concentrators. Nano Energy. 2020;76:105039.

18. Nadal JC, Anderson KL, Dargo S, Joas I, Salas D, Borrull F, Cormack PAG, Marcé RM, Fontanals N. Microporous polymer microspheres with amphoteric character for the solid-phase extraction of acidic and basic analytes. J Chromatography A. 2020;1626:461348.

19. Yan SB, Zhang C, Lv H. Advances in zwitterionic polymers. J Funct Polymers. 2020;33(1):1-14.

20. Ehrmann M, Mathis A, Meurer B, Scheer M, Galin JC. Statistical n-butyl acrylate-(sulfopropyl) ammonium betaine copolymers: 2.Structural studies. Macromolecules. 1992;25(8):2253-61.

21. Chen YJ, Han HJ, Tong HX, Chen $\Pi$, Wanget HB, Ji J, Jin Q. Zwitterionic phosphorylcholine-TPE conjugate for pH-responsive drug delivery and AIE active imaging. ACS Appl Mater Interfaces. 2016; 8(33):21185-92.

22. You YC, Jiao JL, Li Z, Zhu CY. Synthesis and swelling behavior of crosslinked copolymers of neutralized maleic anhydride with other monomers [J]. J Appl Polym Sci. 2003:88(12):2725-31.

23. Zhang CY, Yuan JS, Lu JH, Hou YQ, Xing W, Lu H. From neutral to zwitterionic poly (alpha-amino acid) nonfouling surfaces: effects of helical conformation and anchoring orientation. Biomaterials. 2018;178:728-37.

24. Lau KHA, Sileika TS, Park SH, Sousa AML, Burch P, Szleifer I, Messersmith PB. Molecular design of antifouling polymer brushes using sequence-specific peptoids. Adv Mater Interfaces. 2015;2(1):1400225. 
25. Mrela A, Pawlak Z. Articular cartilage. Strong adsorption and cohesion of phospholipids with the quaternary ammonium cations providing satisfactory lubrication of natural joints. Biosystems. 2019; 176:27-31.

26. Bi LS, Wang ZH, Xia JF, Zhang FF, Xia YZ, Li YH. Preparation and biocompatibility of phosphatidylcholine modified magnetic carbon nanotubes. Acta Materiae Compositae Sinica. 2012;29(3):117-21.

27. Zheng LC, Sundaramb HS, Weic Z, Lia CC, Yuan ZF. Applications of zwitterionic polymers. React Funct Polym. 2017;118:51-61.

28. Skinner M, Johnston BM, Liu YL, Hammer B, Selhorst R, Xenidou I, Perry SL Emrick T. Synthesis of zwitterionic pluronic analogs. Biomacromolecules. 2018;19(8):3377-89.

29. Ohno K, Kitano H, Kondo T, Iwanaga S, Nakamura M, Kamada T. Antibiofouling properties of an amphoteric polymer brush constructed on a glass substrate. Colloid Surface B. 2011;88(1):455-62.

30. Zhang SY, Zou J, Zhang FW, Elsabahy M, Felder SE, Zhu JH, Pochan DJ, Wooley KL. Rapid and versatile construction of diverse and functional nanostructures derived from a polyphosphoester-based biomimetic block copolymer system. J Am Chem Soc. 2012;134(44):18467-74.

31. Li CH, Tian ZH, Liu WT, Li GY. Surface activity of pepsin-solubilized collagen acylated by lauroyl chloride along with succinic anhydride. Mat Sci Eng CMater. 2015;55(14):327-34.

32. Tian ZH, Shen LR, Liu WT, Li GY. Construction of collagen gel with high viscoelasticity and thermal stability via combining cros-linking and dehydration. J Biomed Mater Res A. 2020;108(9):36956.

33. Song Y, Wang YN, Zeng YH, Wu HP, Shi B. Quantitative determinations of isoelectric point of retanned leather and distribution of retanning agent. J Am Leather Chem As. 2018;113:232-8

34. Wang YN, Huang WL, Zhang HS, Tian L, Zhou JF, Shi B. Surface charge and isoelectric point of leather: a novel determination method and its application in leather making. J Am Leather Chem As. 2017; 112(7):224-31.

35. Yu LD, Qiang XH, Cui L, Chen B, Wang XK, Wu XH. Preparation of a syntan containing active chlorine groups for chrome-free tanned leather. J Clean Prod. 2020;270:122351.

36. Xu JL, Liu F, Wang T, Goff HD, Zhong F. Fabrication of films with tailored properties by regulating the swelling of collagen fiber through $\mathrm{pH}$ adjustment. Food Hydrocolloid. 2020;108:106016.

37. Wu XH, Qiang XH, Liu D, Yu LD, Wang XK. An eco-friendly tanning process to wet-white leather based on amino acids. J Clean Prod. 2020;270:122399.

38. Jin LQ, Wang YL, Zhu DY, Xu QH. Effect of an amphoteric acrylic retanning agent on the physical properties of the resultant leather. Adv Mat Res. 2011; 284-286:1925-8.

39. Jin LQ, Liu ZL, Xu QH, Li YC. Synthesis and application of an amphoteric acrylic polyelectrolyte as a retanning agent. J Soc Leather Technol Chem. 2004:88(3):105-9.

40. Li D, Lv SH, Cao Q, Gao FT. Synthesis and properties of an new amphoteric retaning agent. Adv Mat Res. 2012;502:198-202.

41. Ma JZ, Wang W, Yang ZS, Yang DY, Hu GY, Feng LX, Liu CK. Mannich reaction of carboxyl a-H of poly (2-propenoic acid) and its application in tanning. J Am Leather Chem As. 2000;95(4):138-47.

42. Jia L, Gao DG, Lv B, Ma JZ. Application of a clean auxiliary for leather to obtain a low-salt pickling and less chrome tanning process. XXXIII IULTCS: 2015.

43. Li Y, Gao DG, Ma JZ, Lv B. Synthesis of vinyl polymer/ZnO nano composite and its application in leather tanning agent. Mater Sci Forum. 2011;694:1037.

44. Jia L, Ma JZ, Gao DG, Lv B, Zhang J. Application of an amphoteric polymer for leather pickling to obtain a less total dissolved solids residual process. Clean Prod. 2016;139:788-95

45. Jia L, Ma JZ, Gao DG, Lv B, Cheng L. Facile preparation approach of nanocomposite based on water-soluble polymer and layered double hydroxides for the enhancement of leather dyeing. Appli Clay Sci. 2018;152: 22-8.

46. Lv B, Jia L, Ma JZ, Gao DG, Ma D. Effects of chain transfer agents on properties of AA/BA/AM copolymer retanning agents. J Soc Leather Technol Chem. 2017;101:10-5.

47. Ballús $\mathrm{O}$, Palop R, Noguera L, Micó R. Influence of an amphoteric retanning agent on the properties of leather. XXXIII IULTCS; 2015.
48. Lv SH, Yan XL, Gao RJ. Preparation and properties of copolymer of methacrylic acid and acrylamide onto degraded chitosan initiated by HRP/ $\mathrm{H}_{2} \mathrm{O}_{2}$ /ACAC. Appl Mech Mater. 2011;80-81:396-9.

49. $X u$ W, Chai $X Y$, Zhao GH, Li J, Wang $X C$. Preparation of reactive amphoteric polyurethane with multialdehyde groups and its use as a retanning agent for chrome-free tanned leather. J Appl Polym Sci. 2019; 136(37):47940.

50. Wang XC, Yan Z, Liu XH, Qiang TT, Chen L, Guo PY, Yue OY. An environmental polyurethane retanning agent with the function of reducing free formaldehyde in leather. J Clean Prod. 2019;207:679-88.

51. Liu XH, Yue OY, Wang XC, Hou MD, Zheng MH, Jiang HJ. Preparation and application of a novel biomass-based amphoteric retanning agent with the function of reducing free formaldehyde in leather. J Clean Prod. 2020;265: 121796

52. Wang $X C$, Yan $Z$, Liu XH. A green retanning system with function of reducing free formaldehyde in leather. The 11 th Asian International Conference of Leather Science; 2018.

53. Lv B, Ma JZ, Gao DG, Hong L, Yao Q. Characterization and properties of organic silicon modified amphoteric fatliquor. XXXII IULTCS; 2013.

54. Zheng SJ. Preparation of sulfosuccinate amphoteric fatliquoring agent. XXXII IULTCS; 2013.

55. Janardhanan R, Vijayabaskar V, Reddy BSR. Preparation of a new itaconate based amphoteric surfactant for fatliquor applications. J Am Leather Chem As. 2012;107(7):231-42

56. Wang XC, Guo XX, Wang HJ, Guo PY. Effect of linear-Hyperbranched Amphiphilic phosphate esters on collagen fibers [J]. J Agric Food Chem. 2016;65:104-15.

57. Ren LF, Wang XC, Qiang TT, An HR. Synthesis of amphoteric phosphate ester surfactant by polyphosphoric acid and its application in free-chrome collagen fiber. Adv Mat Res. 2010;129-131:271-5.

58. Ballús O, Catalan T, Palop R, Micó R. Influence of naphthalenesulfonic acid derivatives on the dyeing properties of the leather. XXXIV IULTCS; 2017

59. Luo JX, Feng YJ. Synthesis of an amphoteric polymer auxiliary agent and its application to chrome-free leather. J Soc Leather Technol Chem. 2018; 102(6):298-303.

\section{Publisher's Note}

Springer Nature remains neutral with regard to jurisdictional claims in published maps and institutional affiliations.

\section{Submit your manuscript to a SpringerOpen ${ }^{\circ}$ journal and benefit from:}

- Convenient online submission

- Rigorous peer review

- Open access: articles freely available online

High visibility within the field

- Retaining the copyright to your article

Submit your next manuscript at $>$ springeropen.com 